
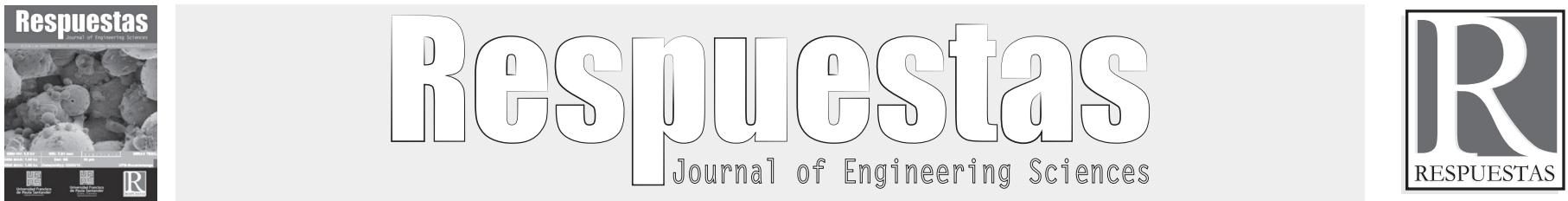

Original Article

https://doi.org/10.22463/0122820X.1740

\title{
Methodology for evaluating linear and non-linear effects in a radio over fiber system
}

\author{
Metodología para evaluar los efectos lineales y no lineales en un sistema de radio sobre fibra óptica \\ Karla Cecilia Puerto-López ${ }^{1 *}$, Rudy Paolo Báez-Parada ${ }^{2}$, Ángel David Torres-Palencia ${ }^{3}$, Dinael Guevara-Ibarra ${ }^{4}$ \\ ${ }^{I^{*}}$ Magister en Ingeniería de Telecomunicaciones, karlaceciliapl@ufps.edu.co, Orcid: 0000-0003-3749-676X, Universidad Francisco de Paula Santander, Cúcuta, \\ Colombia. \\ 2Ingeniero Electrónico, rudypaolobp@ufps.edu.co, Orcid: 0000-0002-9018-8486, Universidad Francisco de Paula Santander, Cúcuta, Colombia. \\ ${ }^{3}$ Ingeniero Electrónico, angeltopa@inaoep.mx, Orcid: 0000-0003-4835-5188, Instituto Nacional de Astronomía Óptica y Electrónica, San Andrés Cholula, México. \\ ${ }^{4}$ Doctor en Ingeniería, dinaelgi@ufps.edu.co, Orcid: 0000-0003-3007-8354, Universidad Francisco de Paula Santander, Cúcuta, Colombia.
}

How to cite: K.C. Puerto-López, R.P. Báez-Parada, A.D. Torres-Palencia and D. Guevara-Ibarra, "Methodology for evaluating linear and non-linear effects in a radio over fiber system”, Respuestas, vol. 23, no. 2, pp. 75-88, 2018

Received on January 29, 2018 - Approved on June 12, 2018.

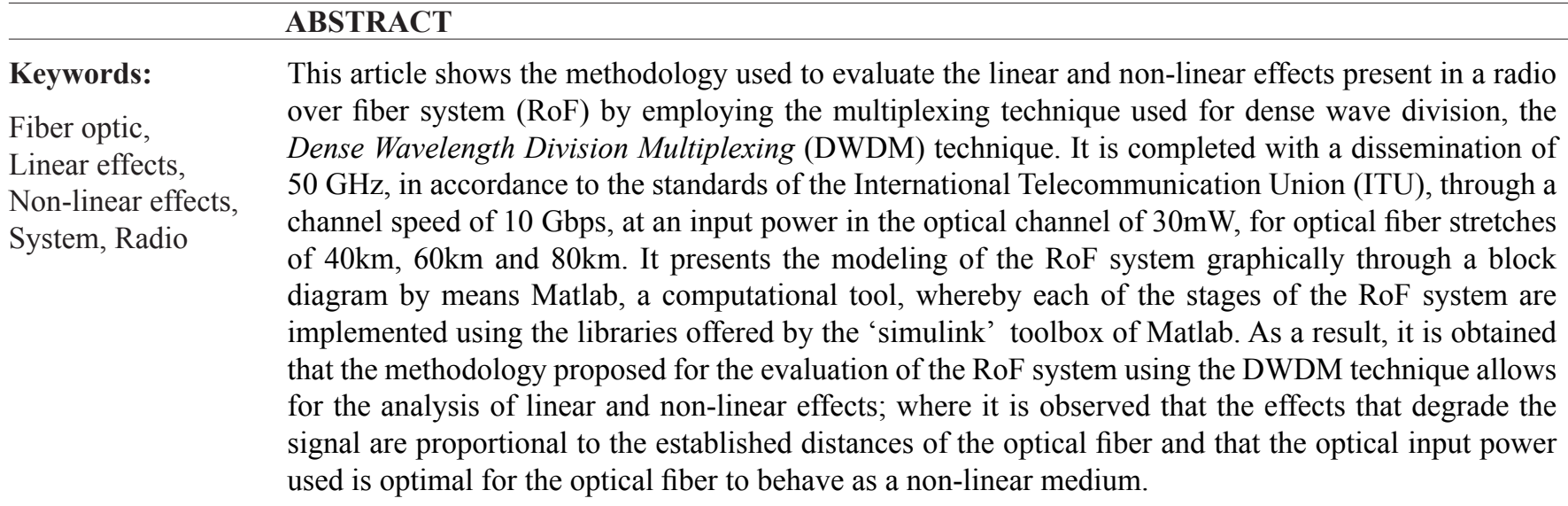

\begin{tabular}{ll}
\hline RESUMEN \\
\hline Palabras clave: & En este artículo, se muestra la metodología para evaluar los efectos lineales y no lineales presentes en \\
Fibra óptica, & un sistema de radio sobre fibra óptica (Radio over Fibre, RoF) empleando la técnica multiplexacion por \\
Efectos lineales, & división de onda densa (Dense Wavelenght Division Multiplexing, DWDM) con esparcimientos de 50GHz, \\
Efectos no & Según las normas de la Unión Internacional de Telecomunicaciones (International Telecommunication \\
lineales, & Union, ITU) con una velocidad de canal de $10 \mathrm{Gbps,} \mathrm{a} \mathrm{una} \mathrm{potencia} \mathrm{de} \mathrm{entrada} \mathrm{en} \mathrm{el} \mathrm{canal} \mathrm{óptico}$ \\
Sistema, Radio & de $30 \mathrm{~mW}$, para tramos de fibra óptica de 40km, 60km y 80km. Se presenta el modelado del sistema \\
& de RoF representado en forma gráfica a través de diagrama de bloques por medio de la herramienta \\
& computacional Matlab, donde se implementan cada una de las etapas del sistema de RoF usando las \\
& librerías ofrecidas por el Toolbox de simulink de Matlab. Como resultado se obtiene que la metodología \\
& propuesta para la evaluación del sistema RoF empleando la técnica DWDM permite analizar los efectos \\
& lineales y no lineales; donde se observa que los efectos que degradan la señal son proporcionales a las \\
& distancias de la fibra óptica establecidas y que la potencia óptica de entrada empleada es óptima para que \\
& la fibra óptica se comporte como medio no lineal.
\end{tabular}

E-mail address: karlaceciliapl@ufps.edu.co (Karla Cecilia Puerto López)

(c) $(1) \Theta$ Peer review is the responsibility of the Universidad Francisco de Paula Santander 


\section{Introduction}

Currently the telecommunications companies are undergoing modernization, because in recent years it has become necessary to implement telecommunications systems that can transport a large amount of information and at the same time offer mobility and flexibility at any time to end users of the access network. On the other hand, it has been reported in the scientific literature as a viable option to satisfy the premises described above, generating hybrid patterns that allow the design and implementation of a single telecommunications infrastructure where both optical communications systems and wireless systems converge [1]. Prototypes have been developed internationally, specifically at Dalian University of Technology, in China, where they implement a RoF system with WDM [2], additionally there are studies of these systems with millimeter wave signals in the $\mathrm{V}$ and $\mathrm{W}$ bands [3]. At a national level, the Pontificia Bolivariana University analyzes the impact on the laser line width requirements due to the linear and non-linear effects introduced by the optical fiber in a WDM-PON transmission system with DPSK modulation format [4]. Locally, at the Francisco de Paula Santander University, a RoF system was modeled under the effects of linear errors using a computational tool [5]. Under these antecedents it can be evidenced that the RoF system under study is with the global, national and local trends.

The integration of optical fiber and wireless networks, such as Radio over Fiber (RoF) systems characterized by combining radio frequency devices with fiber optic links, allowing radio signals from the wireless network to be transported to a remote radiation point by means of optical fiber [6], with an attenuation of $0.25 \mathrm{~dB} / \mathrm{Km}$ at $1550 \mathrm{~nm}$ and providing a large bandwidth of $155 \mathrm{Mb} / \mathrm{s}$ for the transmission of information [7].

However, the implementation of optical fiber as a means of data transmission generates undesired errors causing the deformation of the signal carrying information transmitted by the optical channel. These errors can be of linear character such as attenuation and dispersion or non-linear character errors, which are due to the use of semiconductor optical amplifiers or the existing optical powers of the order of $+10 \mathrm{dBm}$ present in the fiber input [8], causing the appearance of non-linear effects characteristic of the optical fiber, such as Self- Phase Modulation (SPM), Cross-Phase Modulation (XPM), Four-Wave Mixing (FWM), Scattering Stimulated Brillouin (SBS), and Scattering Stimulated Ramman (SRS).

A system with greater information capacity requires more channels and high bandwidth to provide the services demanded by users, hence the emergence of transmission techniques such as Dense Wavelength Division Multiplexing (DWDM) which is governed under the rules of the International Telecommunication Union (ITU) [9].

This article presents the methodology to perform the modeling and simulation of a RoF system based on the DWDM technique using the Matlab computational tool under the Simulink toolbox. The representative data for the system are: $40 \mathrm{~km}$, $60 \mathrm{~km}$ and $80 \mathrm{~km}$ fiber optic section, using the eye diagram and constellation diagram as an evaluation technique.

The exposed methodology allows to analyze in a graphic way each stage of the RoF system with DWDM from the Transmitter, Channel and Receiver; where it can be evidenced that a power greater than $10 \mathrm{~mW}$ generates a widening of the pulses produced by the phenomena of non-linear order.

Below is a description of the methodology used to evaluate the RoF system under these effects using the DWDM technique.

\section{Rof communication system}

Radio over optical fiber systems are mixed systems, characterized by taking advantage of optical fiber to transport radio signals directly to the base station [10]. Figure 1 illustrates the scheme and operation of a RoF system consisting of a Control Station, Base Station and a Mobile Station.

- Optical Transmitter: Its main function is to generate the optical millimetre waves, which are responsible for the radio frequency carrier signal to the base station. [10].

- Fibre channel: This is responsible for transporting 
the radio frequency $(\mathrm{RF})$ signals directly to a remote radiation point according to Figure 1, to the base station. [10].

- Base station: Its main function is opto-electrical conversion. RF signals are sent using high-power amplifiers [10]. linear and non-linear phenomena that degrade the optical signal are presented.

\section{Linear phenomena}

At powers less than $10 \mathrm{dBm}$ at the fibre input, linear phenomena arise and are presented below:

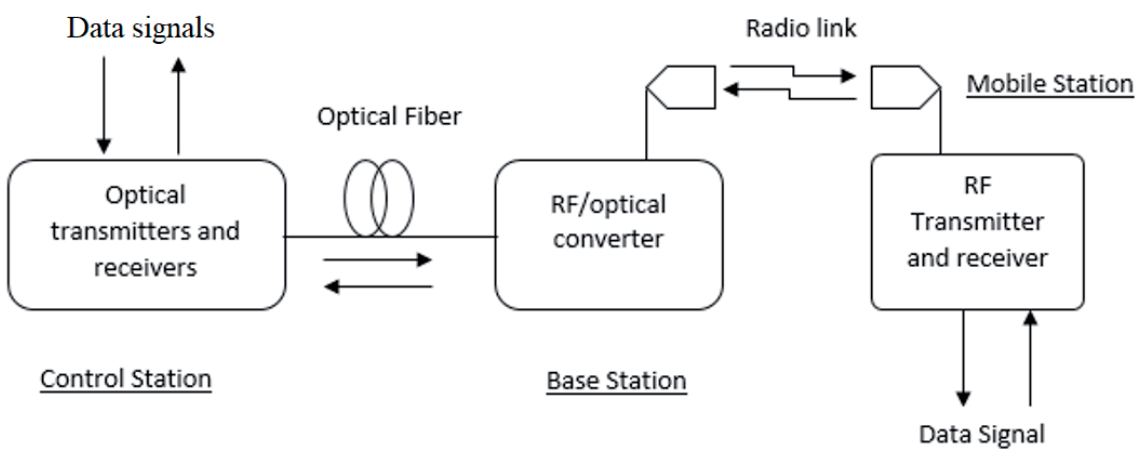

Figure 1. Architecture of a Radio System on Optical Fiber [10].

The representation of the RoF system methodology in the computational tool is represented graphically through blocks as you can see in figure 2; it consists of the transmitter block, optical channel and receiver block.
- Attenuation: Is the loss power of a signal sent through a transmission medium, which can be understood as the loss of power of the light wave when passing through a hard transmission medium [11].

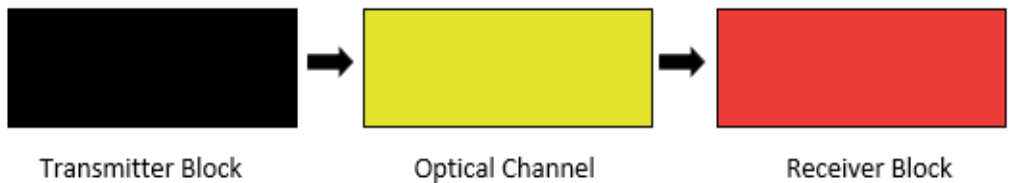

Figure 2. Radio System on Optical Fiber.

\section{Transmitter Block}

This block generates the signal that is sent to the optical channel, where they combine and adapt to the optical channel radio frequency (RF) signals, these signals have a spectrum ranging from 3-300GHz. To adapt the frequencies, ITU standard G.941.1 was used, where the frequencies for the DWDM technique are assigned and is governed by equation $1[9]$.

$$
\text { Fcanal }=193.1+n * 0,05
$$

Where $\mathrm{n}$ is a positive or negative integer value including 0 .

\section{Optical channel}

In this block, RF signals are transported directly to a remote point via optical fiber [10]. At this stage,

$$
\alpha=\frac{10}{L} \log \left(\frac{P_{\text {in }}}{P_{\text {out }}}\right)
$$

Where represents the input power and the one of exit respectively

- Dispersion: It is the variation of the refractive index of an optical mediaum with a wavelength [11].

- Non-linear phenomena: At powers greater than $10 \mathrm{dBm}$ at the fiber input, no linear phenomena are generate and are presented below [12].

- Auto phase modulation: The SPM phnomenon arises because the refractive index of the fibre has a power dependent component. This nonlinear refractive index induces a phase shift that is proportional to the power of the pulse [4]. 


$$
\phi_{N L}=\gamma L_{e f f} *\left(P_{1}\right)
$$

Where () represents the non-linear coefficient and Leff the effective length which depends on the attenuation of the optical fibre.

- Cross phase modulation: La XPM surge debido a que el índice de refracción para una onda depende no sólo de la potencia de esa onda sino también de la potencia de cualquier otra onda que se propague junto a ella [4].

$$
\phi_{N L}=\gamma L_{e f f} *\left(P_{1}+2 P_{2}\right)
$$

- Fourth Wave Mixture: FWM occurs generally when three frecuency carriers with different powers interact inside the fiber to generate a fourth wave. This fourth wave generates new spurious with new frequencies that obey to [4]:

$$
\omega_{i j k}=\omega_{i}+\omega_{j}-\omega_{k}
$$

Where i, j y k, take the values of $1,2,3 \ldots n$.

- Receiving block: The main function is to perform the opto-electric $(\mathrm{O} / \mathrm{E})$ conversion of the signals coming from the transmitter channel [3]. For this process, a photodetector is used and modelled using the following equation.

$$
\Re=\frac{h * f}{e}
$$

Where represents the responsiveness, $h$ the Plank constate, $e$ is the classical electron radius and $f$ represents the central frequency with which the signal is transmitted.

\section{Materials and Methods}

MatLab is a computational tool that allows you to work with the simulink toolbox, which offers a large library for design, analysis and signal processing. The simulink toolbox is used for the design, analysis and evaluation of the methodology proposed for the RoF system under linear and non-linear effects using the DWDM technique; where the methodology is represented in blocks as shown in figure 2 and then the operation of each block is broken down using the libraries offered by the simulink toolbox [6], [13].

\section{Transmitter block:}

The design of this block consists of the signal generation, the optical source and the Mach-Zehnder modulator as shown in Figure 3.

The signal generation block has the function of modulating the RF signal to be taken to electrooptical conversion, using the technique of doublesideband modulation. The optical source block is responsible for generating the optical signal with a frequency stipulated by standard G. 694.1 to be sent to the optical channel, by means of an optical source and thus transmit signals in the third operating window of the optical fiber. The Mach Zehnder modulator block is in charge of converting the RF signal at high frequency to an optical signal and then multiplexing the established optical signals to send them later to the optical channel.

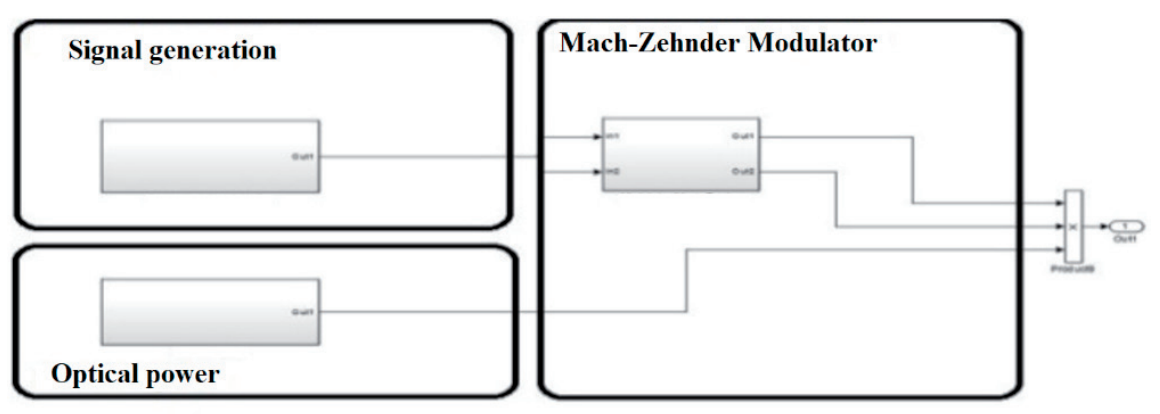

Figure 3. General block diagram of the Optical Transmitter using Simulink® 
Figure 4 shows the internal components of the signal generation blocks, optical source and Mach Zehnder Modulator implemented in Matlabıs Simulink Toolbox (C).

The methodology used for the implementation of the transmitter block diagram starts with the High
Frequency Signal Generation where five signals were generated with EHF carriers and subcarriers modulated using the double sideband method. Table I shows the values of the information carrier and subcarrier signals established for the generation of the analog signal.

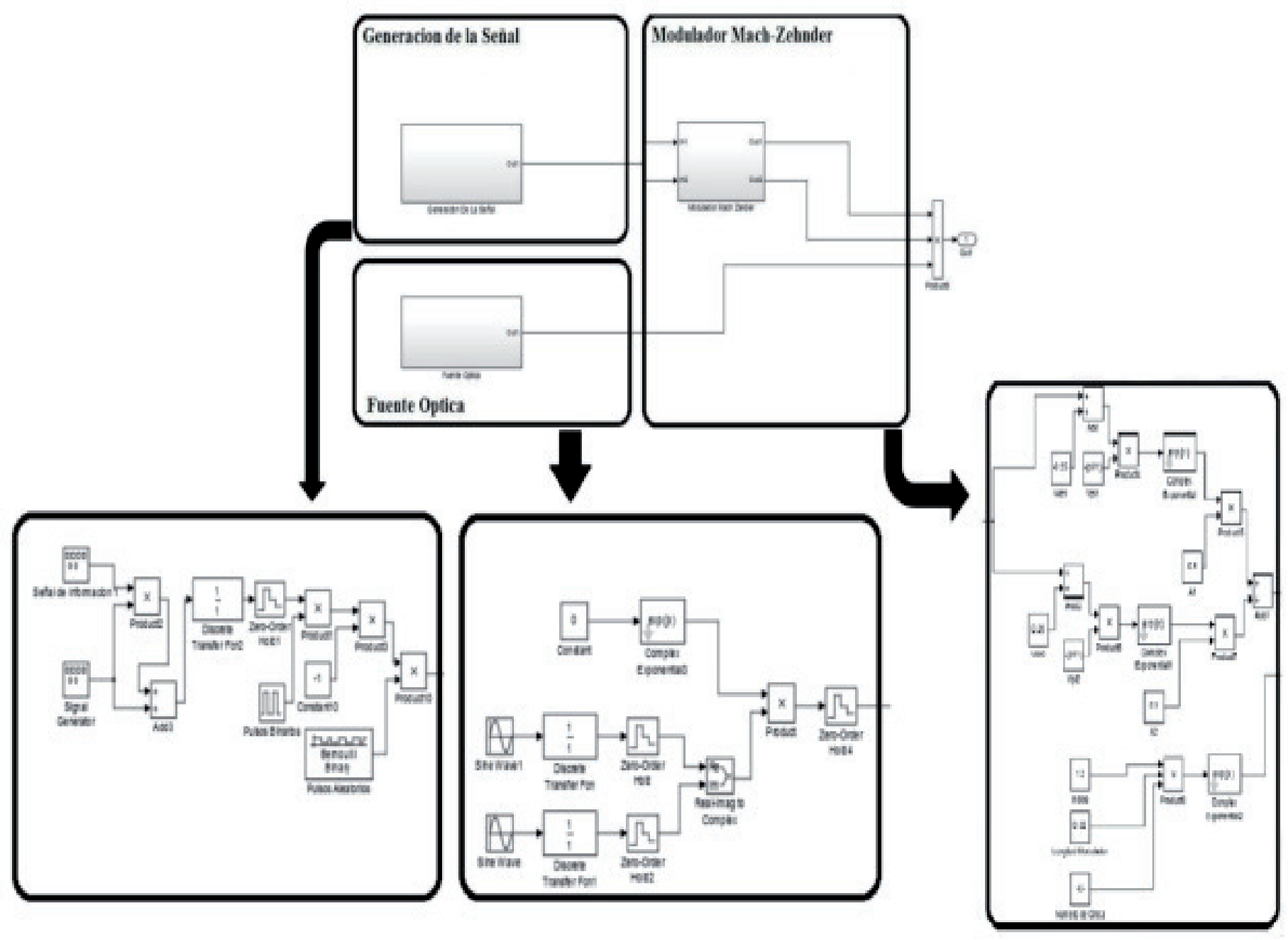

Figure 4. Block diagram of the Optical Transmitter using Simulink

Table I. Generated analog signals

\begin{tabular}{|c|c|c|c|c|c|c|}
\hline Signal & $\begin{array}{c}\text { Frequency } \\
\mathbf{R F}_{\text {Inf }} \\
(\mathbf{G H z})\end{array}$ & $\begin{array}{c}\text { Frequency } \\
\mathbf{R F} \\
(\mathbf{G H z})\end{array}$ & $\begin{array}{c}\text { Angular } \\
\text { Frequency } \\
\mathbf{R F}_{\text {Inf }} \\
(\mathbf{r a d} / \mathbf{s e g})\end{array}$ & $\begin{array}{c}\text { Angular } \\
\text { Frequency } \\
\mathbf{R F} \\
(\mathbf{r a d} / \mathbf{s e g})\end{array}$ & $\begin{array}{c}\text { Signal } \\
\text { Ampplitude } \\
\mathbf{R F}_{\text {Inf }} \\
(\mathbf{V})\end{array}$ & $\begin{array}{c}\text { Signal } \\
\text { Amplitude } \\
\mathbf{R F} \\
(\mathbf{V})\end{array}$ \\
\hline 1 & 3 & 50 & $18.89^{*} 10^{9}$ & $314.16^{*} 10^{9}$ & 1 & 1 \\
\hline 2 & 4 & 50 & $25.13^{*} 10^{9}$ & $314.16^{*} 10^{9}$ & 1 & 1 \\
\hline 3 & 3.5 & 50 & $21.99^{*} 10^{9}$ & $314.16^{*} 10^{9}$ & 1 & 1 \\
\hline 4 & 4.5 & 50 & $28.27^{*} 10^{9}$ & $314.16^{*} 10^{9}$ & 1 & 1 \\
\hline 5 & 5 & 50 & $31.42^{*} 10^{9}$ & $314.16^{*} 10^{9}$ & 1 & 1 \\
\hline
\end{tabular}


For the double sideband modulation the same technique is used for the five generated signals, the signal number 3 is taken as reference and its mathematical equation is governed by equation 7 :

$$
\mathrm{X}(\mathrm{t})=X_{3(t)}=A_{3} *\left(\sin w_{3} * t\right)
$$

Considering the parameters of Table I and replacing the previous equation in equation 2, corresponding to the DBL modulated signal is transformed into the following expression as observed in equation 8 .

$V_{\mathrm{DBL}(\mathrm{t})}=A_{\text {Inf } 3} *\left(\sin w_{\text {Inf } 3} * t\right) * A_{3} * \cos (\mathrm{w} * \mathrm{t})$

Where:

$\mathrm{A}_{\text {Inf3 }}=$ Amplitude of the carrier signal $\mathrm{RF}_{\text {Inf }}$

$\mathrm{W}_{\text {Inf3 }}=$ Frecuencia angular de la señal portadora $\mathrm{RF}_{\text {Inf }}$

$\mathrm{A}_{3}=$ Signal amplitude RF

$\mathrm{W}=$ Angular frequency of the RF carrier signal

To perform the process of multiplexing by dense wave division, the G.694.1 [9] standard is used, which for $50 \mathrm{GHz}$ spacing defines the allowed channel frequencies (in $\mathrm{THz}$ ) according to equation (1). Table II shows the frequency values in $\mathrm{THz}$ for the five different signals implemented in the optical source, taken from standard G.694.1. by means of the external Mach Zehnder modulator. The methodology used proceeds to the analysis of the signal treatment, where the general expression of the optical signal obtained at the output of the Mach Zhender modulator must be determined, for which equation 9 of the electric field of the signal at the input [15] is used.

$$
E_{\text {Out }}=\left[E_{\text {Out }}\right] * e^{j \emptyset_{\text {out }}}
$$

Where equation 9 can be described as follows:

$$
\begin{gathered}
{\left[E_{\text {Out }}\right]=E_{\text {in }} *\left(\operatorname { c o s } \left(\emptyset_{D C}+2 \emptyset_{R f} *\right.\right.} \\
\left.\cos \left(w_{R f} * t+\theta_{R f}\right)\right) * e^{j * \emptyset_{0}}
\end{gathered}
$$

The term that represents the cosine is a term that comes from the double sideband modulation and is given from the following conditions:

- $\theta_{R F 2}-\theta_{R F 1}=\pi$

- $\emptyset_{D C}=-\frac{\pi}{4}$

- $\Delta V=\frac{V_{\pi}}{2}$

Subsequently the signals are multiplexed with the optical carriers with a stipulated central frequency of $193.55 \mathrm{GHz}$, which allows working in the third operating window $(1550 \mathrm{~nm})$ of the monomode optical fiber standardized by ITU standard G.652.

Table II. generated optical signals

\begin{tabular}{|c|c|c|c|}
\hline Signal & $\begin{array}{c}\text { N Value } \\
\text { (Adimensional) }\end{array}$ & $\begin{array}{c}\text { Optical Frequency } \\
\text { (GHz) }\end{array}$ & $\begin{array}{c}\text { Wavelength } \\
(\mathbf{m})\end{array}$ \\
\hline 1 & 11 & $193.65 \mathrm{THz}$ & $1549.2 \mathrm{~nm}$ \\
\hline 2 & 10 & $193.60 \mathrm{THz}$ & $1549.6 \mathrm{~nm}$ \\
\hline 3 & 9 & $193.55 \mathrm{THz}$ & $1550 \mathrm{~nm}$ \\
\hline 4 & 8 & $193.50 \mathrm{THz}$ & $1550.4 \mathrm{~nm}$ \\
\hline 5 & 7 & $193.45 \mathrm{THz}$ & $1550.8 \mathrm{~nm}$ \\
\hline
\end{tabular}

A center frequency of $193.55 \mathrm{THz}$ is used which is the center frequency of the multiplexed signal in the optical channel, this frequency is optimal to operate in a standard single mode fiber which is regulated in standard G.652 of the International Telecommunication Union [14].

Once the millimetre-wave modulated signal has been obtained, the electro-optical conversion is carried out
Optical channel

Figure 5 illustrates the optical channel, which is responsible for transporting the optical signal to the receiver block. For the implementation of the optical channel, three sub-blocks are designed: Nonlinear Phase Offset, Nonlinear Order Parameter and Linear Order Parameter. 


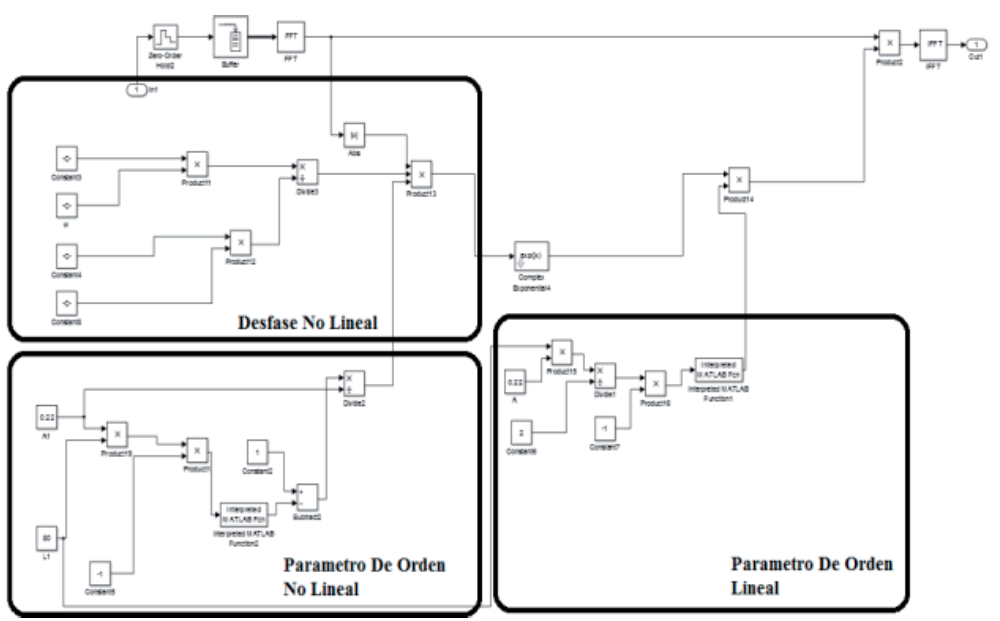

Figure 5. Block diagram for the optical transmission channel using Simulink (C)

For this stage, a standard single-mode optical fibre governed by standard G.652 is used, presenting the linear and non-linear order parameters used in the design of the channel, as shown in Table III.

Table III. Optical channel parameters

\begin{tabular}{|c|c|c|}
\hline Phenomenon & Parameter & Value \\
\hline \multirow{4}{*}{ Orden lineal } & Longitud de fibra óptica & $40,60 \mathrm{y} 80 \mathrm{~km}$ \\
\cline { 2 - 3 } & Atenuación & $0,22 \mathrm{~dB} / \mathrm{km}$ \\
\cline { 2 - 3 } & Velocidad de canal de transmisión & \\
\cline { 2 - 3 } & $\mathrm{P}_{\text {ent }}$ optical channel & $10 \mathrm{Gbit} / \mathrm{seg}$ \\
\cline { 2 - 3 } & Non-linear refractive index & $30 \mathrm{~mW}$ \\
\cline { 2 - 3 } & Modal field diameter & $7.2^{*} 10^{-20}\left(\mathrm{~m}^{2} / \mathrm{w}\right)$ \\
\cline { 2 - 3 } & Pon lineal order & $10^{*} 10^{-6} \mathrm{~m}$ \\
\cline { 2 - 3 } & Quantum Efficiency & 6 \\
\cline { 2 - 3 } & Generation Efficiency FWM $\eta$ & 0.64 \\
\cline { 2 - 3 } & & 1 \\
\hline
\end{tabular}

The effects of linear and nonlinear origin present in the optical fiber are mathematically modeled through Schrödinger's nonlinear equation as observed in equation 11.

$$
\begin{gathered}
\frac{\partial A_{j}}{\partial z}+\beta_{1 j} \frac{\partial A_{j}}{\partial t}+i \frac{\beta_{2 j}}{2} \frac{\partial^{2} A_{j}}{\partial t^{2}}+\frac{\alpha_{J}}{2} A_{j}= \\
i \gamma \cdot\left[\left|A_{j}\right|^{2}+2\left|A_{3-j}\right|^{2}\right] A_{j}
\end{gathered}
$$

On the right side of equation 11 followed by equality represent the non-linear phenomena of optical fiber, where $\gamma$ represents the non-linearity coefficient; the solution of equation 11 without establishing the dispersive parameters $\left(\mathrm{B}_{1} \mathrm{y}_{2}\right)$ are evidenced in the equation 12.

$$
A_{1}=A_{1} * e^{\frac{-\alpha * Z}{2}} * e^{\varphi}
$$

Where is the offset produced by the non-linear phenomena SPM and XPM.

\section{Optical receiver:}

This stage is in charge of receiving the signal after propagating through the optical channel. In the methodology used for the design of the Optical Receiver block, a Photodetector, Filter Bank and a Demultiplexer are used, as shown in figure 6.

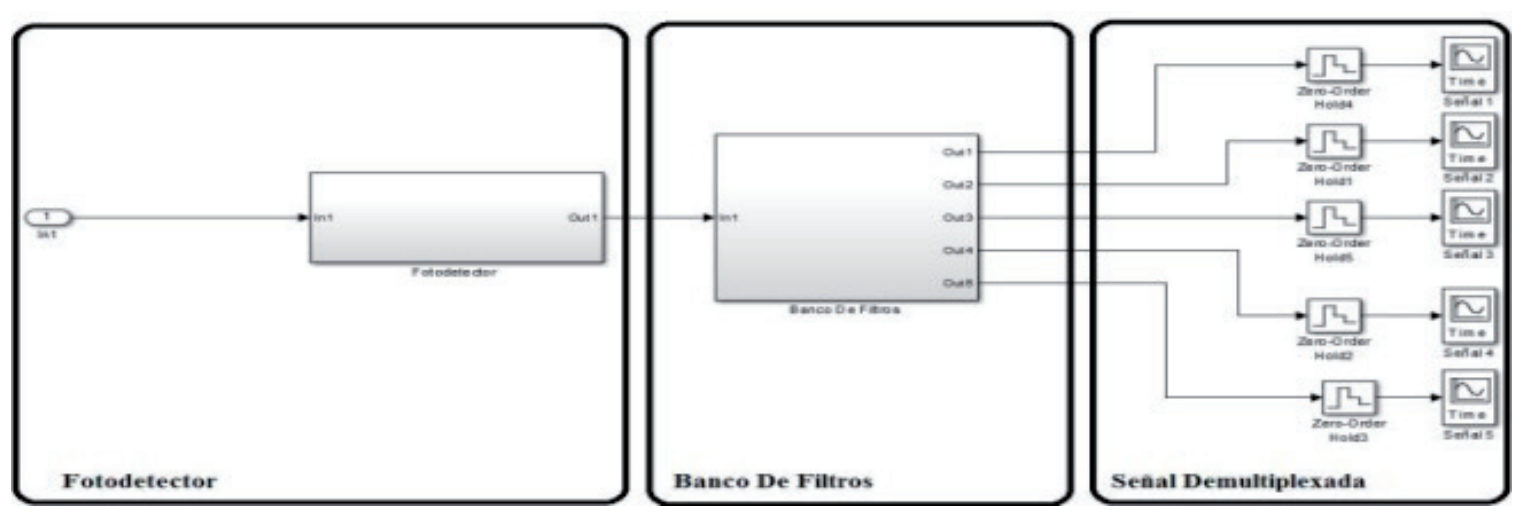

Figure 6. Block diagram for the optical receiver using Simulink $\mathbb{C}$ 
For the implementation of the photodetector in the computational tool, the parameters shown in Table IV are used.

Table IV. Optical channel parameters

\begin{tabular}{|c|c|}
\hline Parameter & Value \\
\hline Accountability & $0.8 \mathrm{~A} / \mathrm{W}$ \\
\hline Load Resistance & $50 \Omega$ \\
\hline Receiver Bandwidth & $10.5 \mathrm{GHz}$ \\
\hline Temperature & $293{ }^{\circ} \mathrm{K}$ \\
\hline Noise Factor & $10 \mathrm{nA}$ \\
\hline $\mathrm{I}_{\text {dark }}$ & $1.69908942 \times 10-10$ \\
\hline $\begin{array}{c}\text { Thermal Current } \\
\left(\mathrm{I}_{\text {TERM }}{ }^{2}\right.\end{array}$ & $1.4285 \times 10-12$ \\
\hline $\begin{array}{c}\text { Trip Current } \\
\left(\mathrm{I}_{\text {SHOT }}{ }^{2}\right)\end{array}$ & $1.3807 \times 10-23$ \\
\hline $\begin{array}{c}\text { Boltzman Constant } \\
(\text { Kg) }\end{array}$ & 0.64 \\
\hline \begin{tabular}{c} 
Quantum Efficiency \\
\hline
\end{tabular}
\end{tabular}

In order to eliminate possible distortions produced by non-linear errors, a bank of filters is used, presented in the Simulink toolbox called Filter Design \& Analysis Tools. Table V shows the characteristics of the filters used to optimise the system.

Table V. Parameters of Filters Implemented in Matlab's
"Filter Design \& Analysis Tools"
\begin{tabular}{|c|c|c|}
\hline Parameters & Filtro 1 & Filtro 2 \\
\hline Type & High-Pass & Low Pass \\
\hline Window Type & Triangular & Triangular \\
\hline Filter Order & 50 & 50 \\
\hline Method & FIR & FIR \\
\hline & & $3 \mathrm{GHz}$ \\
Cutting Frequency & $50 \mathrm{GHz}$ & $3.5 \mathrm{GHz}$ \\
& & $4 \mathrm{GHz}$ \\
& & $4.5 \mathrm{GHz}$ \\
& & $5 \mathrm{GHz}$ \\
\hline
\end{tabular}

Figure 7 shows the components that are part of the Receiver block diagram. The proposed methodology allows to implement step by step the RoF system

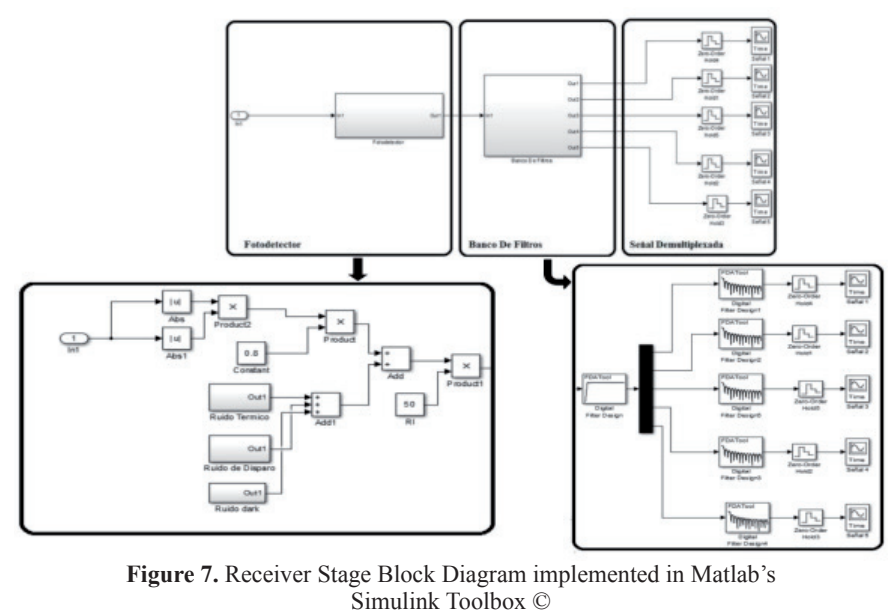

under the effects of linear and non-linear errors using the DWDM technique in the computational tool and thus evaluate the behavior of the signal under these dispersive effects.

\section{System evaluation}

For the evaluation of the RoF system, the technique eye diagram and constellation diagram was used. Figure 8 shows the block diagram implemented in the Simulink toolbox for the eye diagram technique, which consists of an analog/digital converter block and the PCM Modulator block, whose function is to perform the process of converting serial to parallel bits in M (M-aria) samples.

Figure 9 illustrates the block diagram for the constellation diagram evaluation technique, which consists of an analog/digital converter block, PCM Modulator block, and a Phase Shift Modulation block. This block is in charge of performing the signal offset in samples that depend on the $\mathrm{M}$-aria parameter through the M-PSK (phase shift modulator).

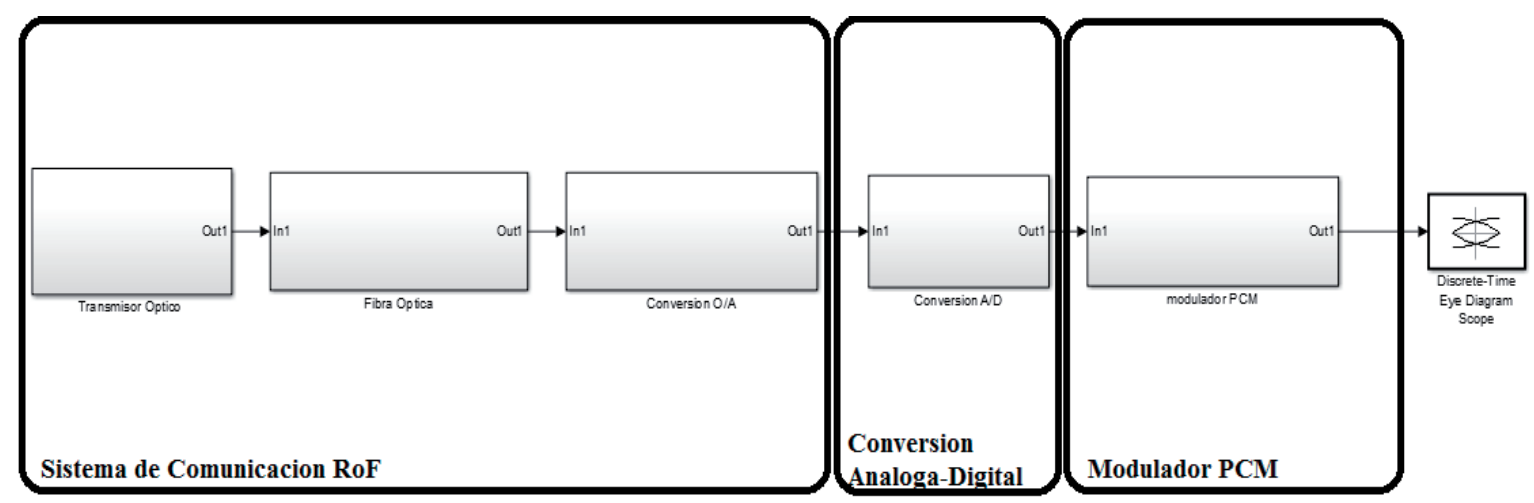

Figure 8. Block diagram for the eye diagram technique using Simulink 


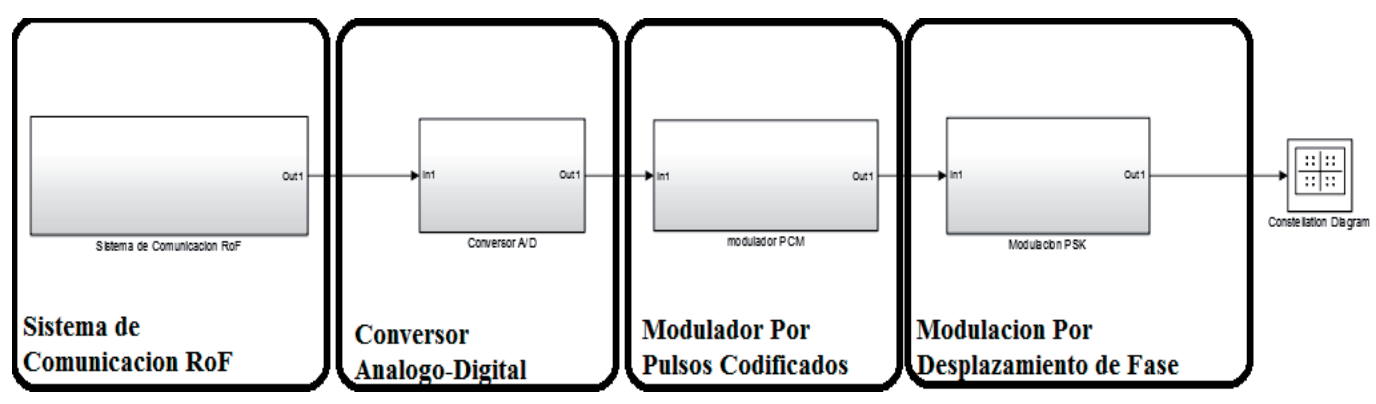

Figure 9. Block diagram for the constellation diagram technique using Simulink $\mathbb{C}$

Table VI shows the corresponding values used and assigned to the blocks in Matlab's Simulink toolbox $\mathbb{C}$.

Table VI. Block parameters in Simulink (C)

\begin{tabular}{|c|c|c|}
\hline Block & Parameter & Value \\
\hline \multirow{4}{*}{ Converter A/D } & Sampling frequency (N) & $F_{N} \geq 2.1 * F_{C}$ \\
\cline { 2 - 3 } & Compressor de A-Law & 87.7 \\
\cline { 2 - 3 } & Uniform Encoder (Bits) & $\log _{2} M$ \\
\hline \multirow{4}{*}{ Modulator PCM } & Buffer & $\log _{2} M$ \\
\cline { 2 - 3 } & Converter from integers to bits & 2 \\
\cline { 2 - 3 } & Unipolar to bipolar converter & 2 \\
\hline \multirow{4}{*}{ ModulatorM-PSK } & Bipolar to unipolar converter & $\log _{2} M$ \\
\cline { 2 - 3 } & Buffer & $\log _{2} M$ \\
\cline { 2 - 3 } & Bit to integer converter & 8 \\
\cline { 2 - 3 } & Nuero M-aria (M) & \multicolumn{1}{c}{$M$} \\
\hline
\end{tabular}

The following are the results obtained in the RoF system under the dispersive effects using the proposed methodology.

\section{Results and Discussions}

With the methodology proposed through the design and implementation of block diagrams for the RoF system through a computational tool, the performance of the proposed methodology is evaluated by performing simulations for different lengths of fiber at $40 \mathrm{~km}, 60 \mathrm{~km}$ and $80 \mathrm{~km}$ respectively.

The objective is to track the signals at the input of the transmitter block and the behavior of these signals in the optical channel under linear and non-linear effects and how it behaves in the receiver block.

Five optical signals generated by the optical source are established as shown in Table II, the same number of signals are generated in parallel with the radio frequency carriers established in Table I, where the electro-optical conversion is performed through the Mach Zender modulator and multiplexed with the optical signals established before entering the transmitter channel. This block is in charge of generating enough optical power to make the optical channel behave as a non-linear medium.

Figure 10 illustrates the power level at the fiber input using Spectrum Analyzer from the Simulink toolbox, which evidences a power level of $14.97 \mathrm{dBm}(30 \mathrm{~mW})$ at a frequency of $193.55 \mathrm{THz}$. 


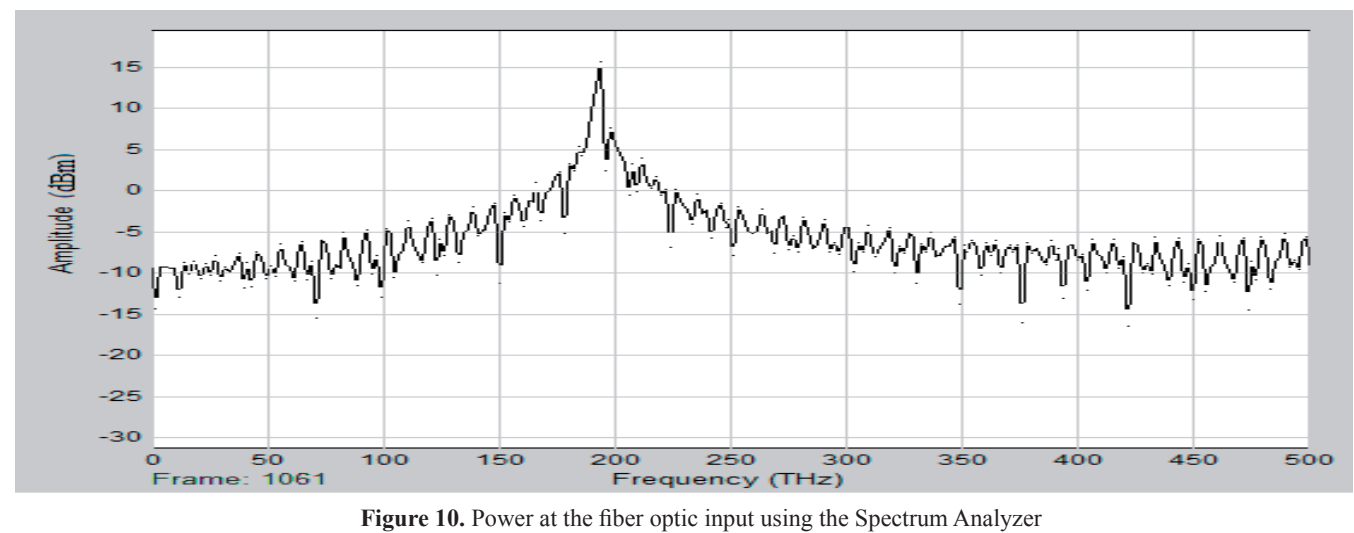

At the output of the transmitter block, the generated channel block as shown in Figure 11. pulses are observed, which then enter the optical

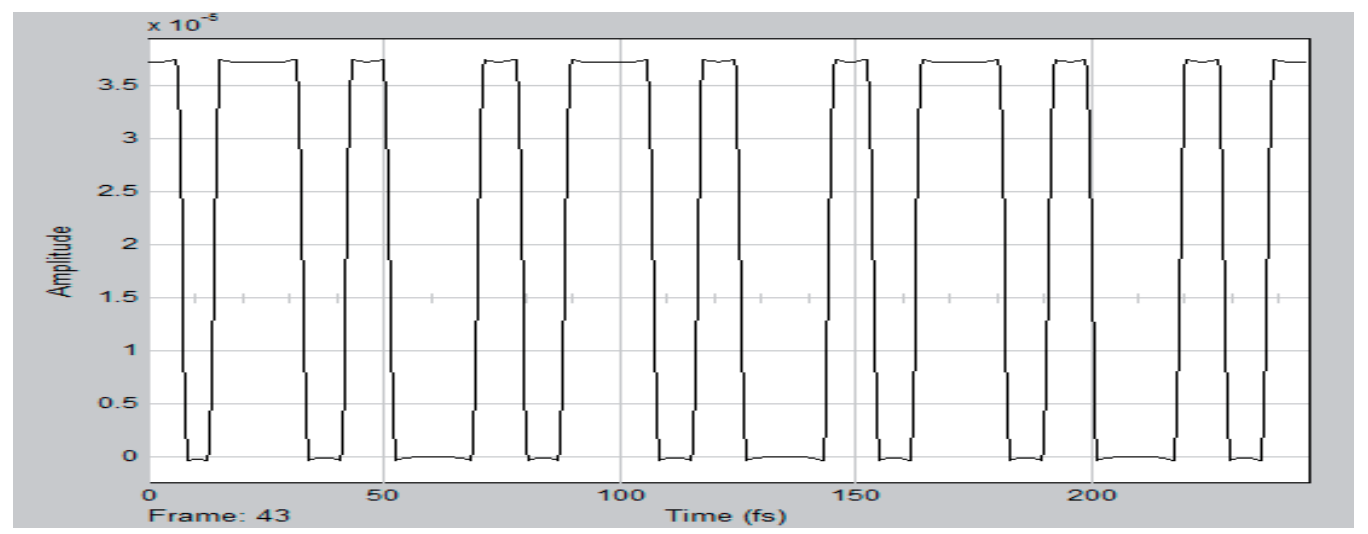

Figure 11. Fiber optic input pulses

For the optical channel, the behavior of signals for different fiber optic sections is observed under the effects of linear and non-linear errors.

Figure 12 illustrates the pulses at the exit of the RoF system for a fibre section at $40 \mathrm{~km}$, where there is evidence of a widening of the pulses compared to the input pulses as shown in Figure 11. This widening is produced by the non-linear phenomena SPM and XPM.

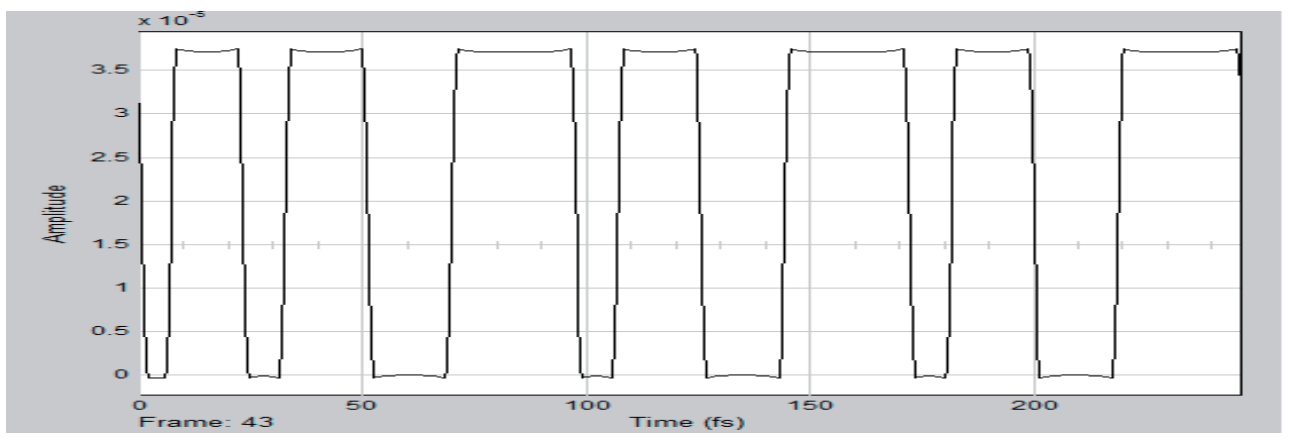

Figure 12. Output pulses for a $40 \mathrm{~km}$ fibre optic section

Figure 13 illustrates the pulses at the exit of the RoF system for a stretch of fibre at $60 \mathrm{~km}$, where there is evidence of a more notable widening of the pulses compared to the input pulses as shown in Figure 11. 


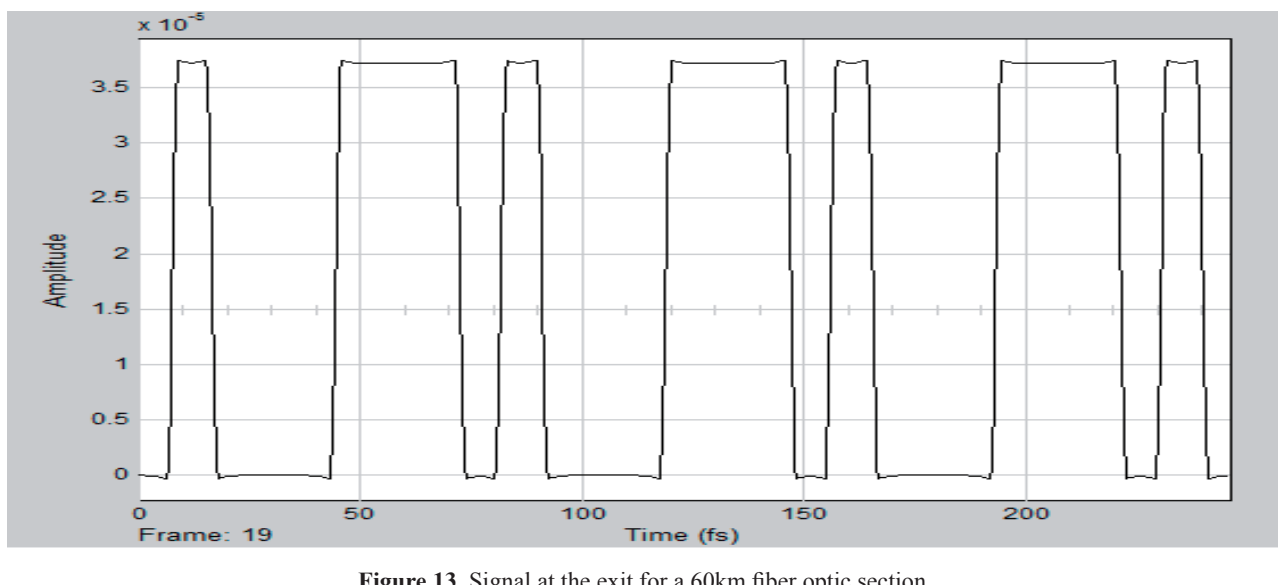

Figure 13. Signal at the exit for a $60 \mathrm{~km}$ fiber optic section

Figure 14 illustrates the pulses for a fiber optic section at $80 \mathrm{Km}$, where it is evident that the pulses widen more with respect to Figure 11 due to SPM and XPM phenomena, which will produce a lower binary regime and the signal will be lost due to power loss.

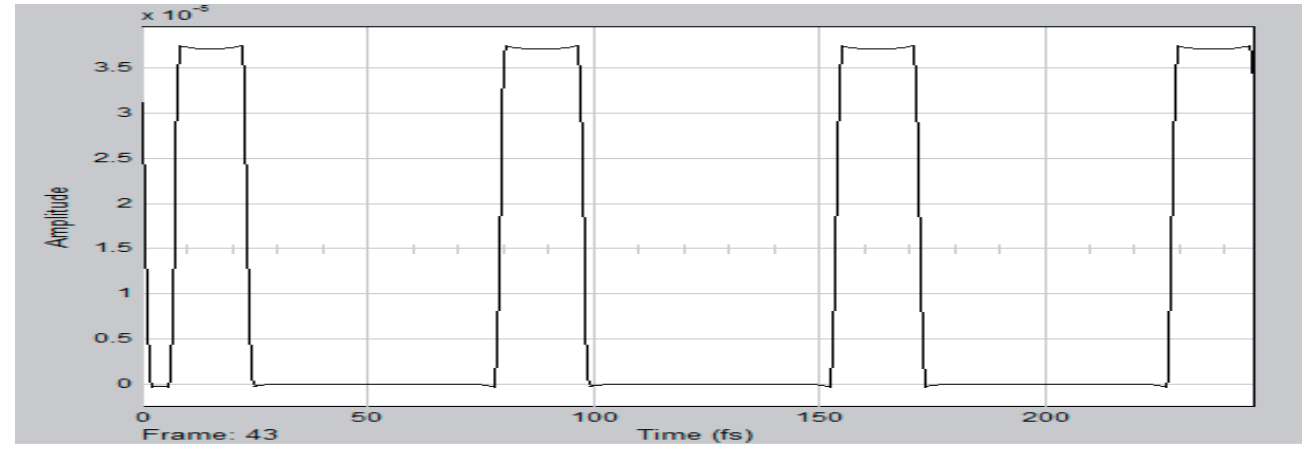

Figure 14. Output pulses for an $80 \mathrm{~km}$ fiber optic section

The receiver block shows the degradation of the signal produced by the attenuation of the optical fiber, for the fiber lengths of $40 \mathrm{~km}, 60 \mathrm{~km}$ and $80 \mathrm{~km}$ which is degraded in an attenuation factor of 0.22 $\mathrm{dB} / \mathrm{km}$ compared to Figure 11 .

It is evident that the methodology designed for the RoF communication system is viable since it allows to evaluate the behavior of the signal through the fiber. The evaluation of the signal transmitted by the RoF communication system is carried out by means of established blocks such as the eye diagram and constellation diagram, where the distance of $80 \mathrm{~km}$ is established as a reference for the evaluation of the signal behavior since it is the most extensive stretch of the RoF system.

Figure 15 illustrates the result of the block diagram implemented in Matlab Simulink (C) as shown in
Figure 8 , of the signal evaluation technique as the eye diagram for a distance of $80 \mathrm{~km}$, the conversion of samples of fixed binary numbers is performed through the PCM modulator, where this number of samples depends on the parameter M-aria (M) which is assigned a dimensionless value of 8 . It is evident that the signal has no noise or distortion, this shows that the signal is transmitted is optimal at a distance of $80 \mathrm{Km}$. 


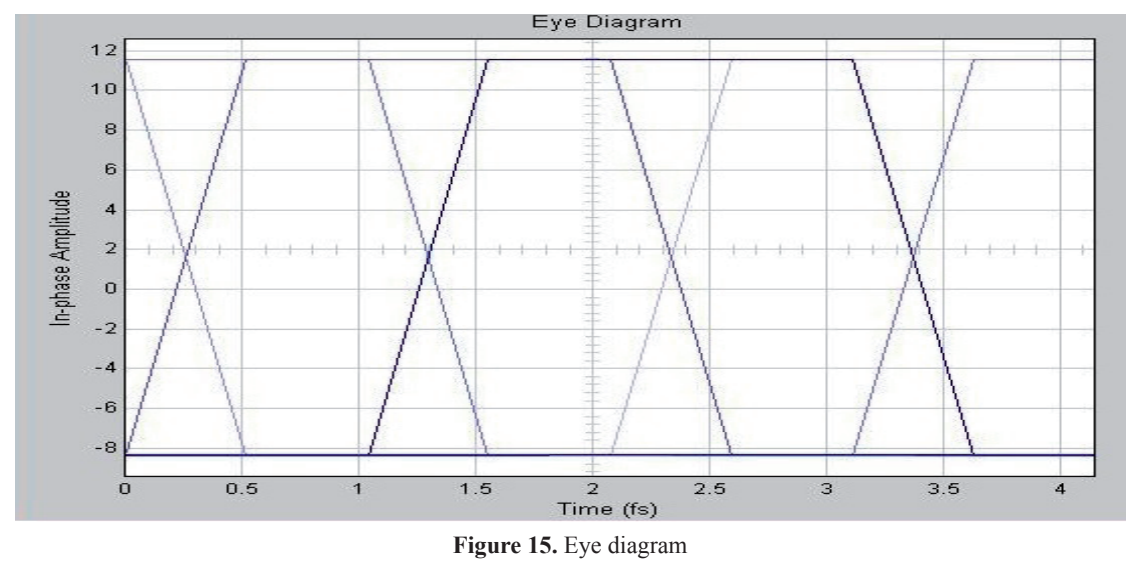

Figure 16 illustrates the constellation diagram, which is the result of the block diagram implemented in Matlab simulink as shown in Figure 9, where the phases produced by the M-PSK modulator are evidenced, where $M$ establishes the number of outputs that in this case is assigned a dimensionless value of 8 and correspond to the same phases of outputs of the figure in question. There is a phase shift of the signal of $\pm 22.5^{\circ}$ during the transmission, each phasor presents a condition called tritibit which indicates that there are three bits for each signal evidenced by the yellow dots. It is observed that the signal does not present any noise or distortion.

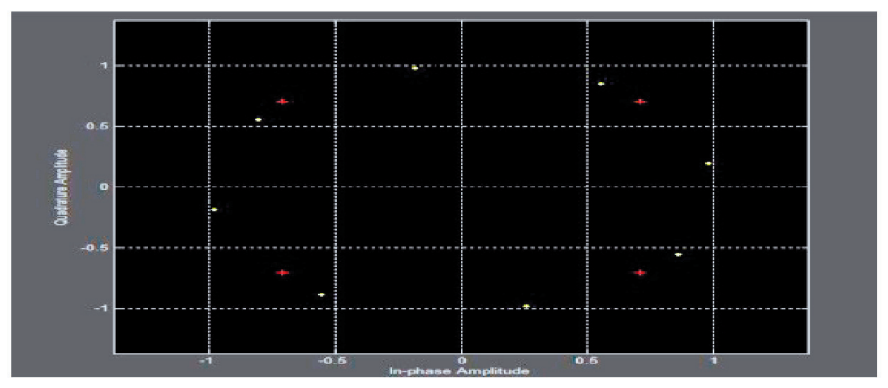

Figure 16. Carrier constellation diagram

The following are the conclusions obtained from the proposed methodology for evaluating the RoF system under the effect of linear and non-linear errors.

\section{Conclusions}

The Simulink Toolbox is a versatile tool that allows you to make designs based on models and represent them graphically, the RoF system based and designed on a mathematical model could be implemented graphically in the Simulink Toolbox using block diagrams; where the behavior of signals through the optical fiber was evaluated under the effects of linear and non-linear errors using the DWDM technique; where it is evident that the RoF system is optimal at distances of $80 \mathrm{~km}$ which is the most extensive fiber optic stretch that was assigned for the development of the RoF system model.

The methodology proposed for the evaluation of the RoF system using the DWDM technique allows the analysis of linear and non-linear effects; where it is observed that the effects that degrade the signal are proportional to the distances of the established optical fiber and that the input optical power used is optimal for the optical fiber to behave as a non-linear medium.

The representation of the RoF system through blocks in the computational tool allows to evaluate the behavior of the signal as it is observed in the figures 12,13 and 14 where there is an ensachamiento of the pulses to the exit of the fiber this is produced by the chirp generated by the nonlinear phenomena XPM and SPM therefore it is evidenced that the power used of $30 \mathrm{~mW}$ generates that the optical fiber behaves like nonlinear means.

The implementation of the receiver block and the sub-blocks of the eye diagram and the constellation diagram for the evaluation of the system show that the optical power at the input of the $30 \mathrm{~mW}$ fiber is optimal for the operation of a digital format modulator such as the M-PSK, since it illustrates that the signal does not present distortion by the noise generated by the FWM phenomenon at the established wavelength (1550nm). 


\section{References}

[1] C. Hernández, G. Enrique, S. Alfaro y G. Paola, "Software de simulación de diferentes tipos de modulación de señales de radiofrecuencia sobre fibra óptica", Umbral Científico, no. 9, pp. 76-84, 2006.

[2] A. Liu, H. Yin, B. Wu, "High-efficient fullduplex WDM-RoF system with sub- central station", Optics Communications. Vol. 414, pp. 72-76, 2018. https://doi.org/10.1016/j. optcom.2017.12.068

[3] T. Yang, M. Gao, J. Qian, Y. Zou, L. Xiang, G. Shen. A novel radio-over-fiber system with dual millimeter-wavesignals generated simultaneously. School of Electronics and Information Engineering, Soochow University. 2016. http://dx.doi.org/10.1016/j. ijleo.2016.04.068

[4] J. Álvarez, F. Amaya. Impacto de los efectos lineales y no lineales en el requerimiento del ancho de línea del transmisor en sistemas WDM-DPSK. Revista UIS Ingenierías, vol. 14, no. 2, p.p. 35-45, 2015.

[5] A. Torres, K. C. Puerto, D. Guevara, "Efectos lineales presentes en un sistema de radio sobre fibra óptica empleando multiplexación por división en longitud de onda", ETCM 2016, Guayaquil , Ecuador, 2016.

[6] N. Masabanda, N. Marmol, “Análisis y Simulación de un Enlace de Radio sobre Fibra Óptica (ROF) a 60 GHz". Disponible en: http://dspace.ups.edu.ec/ bitstream/123456789/5356/1/UPS-ST001033. pdf.

[7] F. Ramos. "Estudio de efectos no lineales en dispositivos fotónicos y su aplicación en sistemas de radio sobre fibra". Tesis Doctoral, Universidad Politécnica de Valencia, Abril 6 del 2009.

[8] J. Pérez. "Coexistencia e Integración de Comunicaciones Inalámbricas en Sistemas de Transmisión Ópticos”. Universidad Politécnica de Valencia, Departamento de Comunicaciones. pp. 1-193, 2009.

[9] Unión Internacional de Telecomunicaciones [online]. Disponible en: https://www.itu.int/ itu-t/recommendations/rec.aspx? rec $=10868$

[10] Francisco R. Pascual, "Estudio de los Efectos no lineales en dispositivos Fotonicos y su aplicación en sistemas de radio sobre fibra óptica”.

[11] M. L. Calvo "Dispersion Cromática" disponible.http://webs.ucm.es/info/giboucm/ Download/chromatic_dispersion.pdf

[12] F. Gómez, L. A. Garcia, K. C. Puerto, D. Guevara "Modelado De Los Fenómenos No Lineales Generados Por El Efecto ElectroÓptico Kerr En Una Transmisión Por Fibra Óptica", Revista Colombiana de Tecnologías de Avanzada, vol. 2, no. 28, pp. 82-87, 2016

[13] Mathworks.com [online]. Disponible en: https://la.mathworks.com/products/simulink. html

[14] Unión Internacional de Telecomunicaciones norma G.652 [online]. Disponible en: https:// www.itu.int/rec/T-REC-G.652/es

[15] F. Marangione. Modelo Simulink para redes de comunicaciones ópticas multiservicio. 2007. Valencia, España.

[16] A. Torres, K. C. Puerto, D. Guevara, "Efectos lineales presentes en un sistema de radio sobre fibra óptica empleando multiplexación por división en longitud de onda", ETCM 2016, Guayaquil, Ecuador, 2016.

[17] G. Campuzano "Telecomnicaciones Radio Sobre Fibra" disponible [En Linea]. http:/www. mty.itesm.mx/die/ddre/transferencia/67/67III.03.html.

[18] G. P. Agrawal, "Fiber-Optic Communication Systems". 4 a ed. New York, USA: John Wiley \& Sons. 2002. 
[19] K. C. Puerto, B. Medina, L.L. Camargo "Efecto De La Dispersión Cromática En Un Sistema Híbrido", Revista Colombiana de Tecnologías de Avanzada, vol. 2, no. 24, pp. 51-58, 2014.

[20] L. A. Garcia, K. C. Puerto, D. Guevara, "Efectos de la Modulación de Fase Cruzada en comunicaciones por fibra óptica", VII BETCON, 2015, La Paz, Bolivia, 2015.

[21] A. Stöhr, A. Akrout, R. Buß, B. Charbonnier, F. van Dijk, A. Enard, S. Fedderwitz, D. Jäger, M. Huchard, F. Lecoche, J. Marti, R. Sambaraju, A. Steffan, A. Umbach, M. Weiß. $60 \mathrm{GHz}$ radio-over-fiber technologies for broadband wireless services. Optical Society of America, Journal Of Optical Networking. Vol. 8, No. 5 pp. 471-487, 2009. 